\title{
Osmotin-Like Protein Gene from Panax notoginseng Is Regulated by Jasmonic Acid and Involved in Defense Responses to Fusarium solani
}

\author{
Qin Zhao, ${ }^{1,2}$ Bingling Qiu, ${ }^{1,2}$ Shan Li, ${ }^{1,2}$ Yingpeng Zhang, ${ }^{1,2}$ Xiuming Cui,,2 and Diqiu Liu1,2,† \\ ${ }^{1}$ Faculty of Life Science and Technology, Kunming University of Science and Technology, Kunming, 650500, Yunnan, China \\ 2 Yunnan Provincial Key Laboratory of Panax notoginseng, Kunming, 650500, Yunnan, China \\ Accepted for publication 14 April 2020.
}

\begin{abstract}
Osmotin and osmotin-like proteins (OLPs) play important roles in plant defense responses. The full-length cDNA sequence of an $O L P$ gene was cloned from Panax notoginseng using rapid amplification of cDNAend technology and named PnOLP1. A quantitative reverse transcriptionPCR analysis showed that the signaling molecules methyl jasmonate, salicylic acid, ethylene, and hydrogen peroxide induced PnOLP1 expression to different degrees. In addition, the expression level of PnOLP1 rapidly increased within $48 \mathrm{~h}$ of inoculating $P$. notoginseng with the root rot pathogen Fusarium solani. Subcellular localization revealed that PnOLP1 localized to the cell wall. A prokaryotic expression vector containing PnOLP1 was constructed and transformed into Escherichia coli BL21 (DE3), and in vitro antifungal assays were performed using the purified recombinant PnOLP1 protein. The recombinant PnOLP1 protein
\end{abstract}

ABSTRACT had strong inhibitory effects on the mycelial growth of $F$. oxysporum, $F$. graminearum, and $F$. solani. A plant $P n O L P 1$-overexpression vector was constructed and transfected into tobacco, and the resistance of T2 transgenic tobacco against $F$. solani was significantly enhanced compared with wild-type tobacco. Moreover, a PnOLP1 RNAi vector was constructed and transferred to the $P$. notoginseng leaves for transient expression, and the decrease of PnOLP1 expression level in $P$. notoginseng leaves increased the susceptibility to $F$. solani. Thus, PnOLPl is an important disease resistance gene involved in the defense responses of $P$. notoginseng to F. solani.

Keywords: antifungal activity, elicitors, osmotin-like protein, overexpression in tobacco, root rot
Pathogenesis-related proteins (PRs) are a class of disease-related proteins induced by pathogen infections and abiotic factor stimulation, and PRs participate in plant defense responses through the induced systemic resistance, systemic acquired resistance and other ways. PR proteins are classified into 17 families (PR-1 to PR-17) based on their sequences, serological relationships, and biological activities (Van Loon et al. 2006). The $P R-5$ gene family is mainly composed of thaumatins, thaumatin-like proteins (TLPs), osmotins, and zeamatins (Hakim et al. 2018). Osmotin and the osmotin-like proteins (OLPs) are prevalent in plants. The Arabidopsis thaliana OLP gene (ATOSM) corresponds to a single copy gene (Capelli et al. 1997). Moreover, an OLP was purified from the seeds of Benincasa hispida, and its genomic clone was isolated and confirmed as a singlecopy gene (Shih et al. 2001). The strawberry (Fragaria $\times$ ananassa) $O L P$ gene, designated $F a O L P 2$, represents a multigene family (Zhang and Shih 2007). In addition, the Solanum nigrum OLP gene, SniOLP, belongs to a small multigene family (Jami et al. 2007).

There are many reports on the induction of OLP genes in different plants by a variety of biotic and abiotic stresses. When $5 \mathrm{mM}$ ethyl gallate was sprayed on tobacco (Nicotiana tabacum) plants, some defense-related genes, including osmotin, were up-regulated (Goupil et al. 2017). Salicylic acid (SA), abscisic acid (ABA), and mechanical wounding trigger the significant induction of strawberry $O L P 2$ within 2- to 6-h posttreatment (Zhang and Shih 2007). After a heat-shock pretreatment on germinating seeds of

†Corresponding author: D. Liu; diqiuliu@126.com

Funding: This work was financially supported by two grants received from the National Natural Sciences Foundation of China (81560610) and Yunnan Ten Thousand Talents Plan Young \& Elite Talents Project.

*The $\boldsymbol{e}$-Xtra logo stands for "electronic extra" and indicates that one supplementary figure is published online.

The author(s) declare no conflict of interest.

(c) 2020 The American Phytopathological Society winter wheat (Triticum aestivum), the transcriptome profiling indicated that the expression levels of some stress-related genes, such as heat-shock proteins and osmotins, are up-regulated (Zhang et al. 2016). The expression levels of OSM1 from pepper (Capsicum annuum) and OSM from Olea europaea can be induced by cold acclimation (Hong et al. 2004). After being infected with Colletotrichum coccodes, Xanthomonas campestris, and Phytophthora capsici, the pepper $O S M 1$ gene was also rapidly expressed at the transcriptional level (Hong et al. 2004). At $72 \mathrm{~h}$ after inoculation with Aspergillus ochraceus, proteomics using two-dimensional gel electrophoresis revealed that Arabidopsis OSM34 is involved in defense responses (Hao et al. 2015). The OSMs in S. lycopersicum, $S$. tuberosum, Lycopersicon cerasiforme, and $S$. commersonii are greatly induced by Ralstonia solanacearum infection (Baichoo and Jaufeerally-Fakim 2017).

A homology modeling analysis showed that the $S$. nigrum OLP protein contains an acidic fissure region that may interact with the carbohydrate component of the fungal cell wall (Jami et al. 2007). The osmotin protein permeabilizes the plasma membrane and kills the fungal cells (Ramana Rao et al. 2011). The osmotin (CpOsm) from latex of Calotropis procera may induce membrane permeabilization in the spores and hyphae of Fusarium solani, as indicated by their uptake of the fluorogenic dye propidium iodide (de Freitas et al. 2011a). In addition, the CpOsm protein is relatively thermostable and retains its antifungal activity over a wide $\mathrm{pH}$ range (Ramos et al. 2015). Antimicrobial tests showed that Osm1 derived from Theobroma cacao expressed in Escherichia coli inhibited the growth of yeast (Pichia pastoris) in vitro (Falcao et al. 2016). Recombinant osmotic proteins from tobacco have significant antimicrobial activities, particularly against fungal pathogens causing candidiasis and otitis (Candida parapsilosis and Candida tropicalis) and two common food pathogens (Debaryomyces hansenii and Torulaspora globosa) (Viktorova et al. 2017). The osmotins and OLPs are important parts of plant immune system.

Panax notoginseng (Burk) F. H. Chen is an important traditional Chinese herbal medicine, and it is mainly artificially cultivated in 
Wenshan Prefecture, Yunnan Province. The growth cycle of $P$. notoginseng is very long and requires warm and damp growing conditions. Therefore, there are a variety of diseases and pests that seriously endanger the growth and development of $P$. notoginseng. The root rot disease is the most serious problem limiting the production of the $P$. notoginseng and mainly caused by $F$. solani (Chen et al. 2016; Miao et al. 2006). It is unfortunate that there is no specific and environmentally friendly approach to control root rot disease in $P$. notoginseng (Tang et al. 2019). In our previous study, exogenous applications of methyl jasmonate (MeJA) on $P$. notoginseng roots increased the resistance to root rot caused by $F$. solani infections, and a unigene encoding the OLP responded to the exogenous MeJA and $F$. solani infection through transcriptome sequence of $P$. notoginseng roots (Liu et al. 2019). In this study, the gene expression and functional analysis of this $O L P$ gene $(P n O L P 1)$ were performed to further understand the defense mechanisms involved in $P$. notoginseng's response to $F$. solani exposure.

\section{MATERIALS AND METHODS}

Plant and fungal materials. The cultivated $P$. notoginseng has become a highly mixed population during artificial planting over a long period of time. Therefore, the material used in this study is the cultivated $P$. notoginseng population. The healthy 1 -year-old cultivated $P$. notoginseng population was collected from a $P$. notoginseng planting base, and then was transplanted in a greenhouse with double shady nets. The sterile nontransgenic tobacco ( $N$. tabacum L. 'Xanthi') seedlings were cultured in a light incubator $\left(25^{\circ} \mathrm{C}, 16\right.$-h light cycle). Three pathogenic fungi, F. solani, F. oxysporum, and F. graminearum, were preserved and characterized in our laboratory, and the fungi were activated on potato dextrose agar (PDA) medium before being used.

Chemical treatments and inoculation. To analyze the expression pattern of the PnOLP1 gene, the concentrations of four plant elicitors including the SA, MeJA, ethephon (ETH), and hydrogen peroxide $\left(\mathrm{H}_{2} \mathrm{O}_{2}\right)$, were determined by referring to the chemical treatment method in Wang et al. (2019). The $P$. notoginseng seedlings showed normal growth after independent treatment with SA $(200 \mu \mathrm{M} / \mathrm{liter}), \mathrm{JA}(100 \mu \mathrm{M} / \mathrm{liter}), \mathrm{ETH}(1 \mathrm{mM} /$ liter), and $\mathrm{H}_{2} \mathrm{O}_{2}(1 \mathrm{mM} /$ liter $)$ for 1 month. The $P$. notoginseng roots were dipped in MeJA, ETH, and SA solution with the aforementioned concentrations for $30 \mathrm{~min}$, respectively. The treated roots were collected at 4-, 12-, 24-, 48-, and 72-h posttreatment, respectively. For $F$. solani inoculation, the $P$. notoginseng roots were pretreated with MeJA (100 $\mu \mathrm{mol} /$ liter) for $30 \mathrm{~min}$. After $24 \mathrm{~h}$, the roots were then infected with a suspension of $F$. solani $\left(2 \times 10^{6} \mathrm{spores} / \mathrm{ml}\right)$ for $30 \mathrm{~min}$, and then the infected roots were harvested at 4-, 12-, 24-, 48-, and 72-h postinoculation, respectively. The $P$. notoginseng roots pretreated with sterile water were used as a control for the chemical treatments and fungal inoculation. All the treatments and inoculation were performed with three biological replicates, and the $P$. notoginseng samples were frozen in liquid nitrogen and stored at $-80^{\circ} \mathrm{C}$ before RNA extraction.

Bioinformatics analyses. The full-length cDNA of PnOLP1 was cloned using a SMART RACE cDNA Amplification Kit (Clontech, U.S.A.). The gene-specific primers for $O L P$ are listed in Table 1. Some OLP protein sequences show high homologies with PnOLP1 were downloaded from the NCBI website after searching protein data with blastp tool. In addition, several plant OLP and osmotin genes were reported to be involved in defense response to stress, and the protein sequences of these genes were also included in the phylogenetic analysis. The unrooted tree was constructed with the neighbor-joining method using MEGA software after the multiple alignment with ClustalX, and the bootstrap values were calculated from 1,000 replicates. The protein localization prediction in plants was analyzed using the PredictProtein tool (https:// www.predictprotein.org:443/). The signal peptide prediction was performed using the SignalP 4.1 Server (http://www.cbs.dtu.dk/ services/SignalP/). The protein disulfide bonds were predicted using the PROSITE online tool (https://prosite.expasy.org).

Quantitative reverse transcription-PCR (qRT-PCR). The qRT-PCR was used to analyze the expression level of PnOLP1 gene at different time periods after inoculation with $F$. solani or after treatment with MeJA, ETH, $\mathrm{H}_{2} \mathrm{O}_{2}$, and SA. The internal reference gene is the $P$. notoginseng actin-2 gene (PnACT-2, KF815706.1). The methods of RNA extraction and cDNA synthesis were the same as those of Liu et al. (2018). The qRT-PCR reaction system contained $2 \mu \mathrm{l}$ of cDNA template, $10 \mu \mathrm{l}$ of $2 \times$ Go Taq qPCR Master Mix (Promega, U.S.A.), $6.8 \mu \mathrm{l}$ of RNase-Free $\mathrm{ddH}_{2} \mathrm{O}, 0.6 \mu \mathrm{l}$ of forward primer, and $0.6 \mu \mathrm{l}$ of reverse primer (Table 1). The amplification conditions and equipment used for PCR were consistent with the qRT-PCR method in Liu et al. (2018). All the qRT-PCR assays included three biological repeats.

Subcellular localization of the PnOLP1 protein. The subcellular localization vector pBINm-gfp5-ER was used in this assay. Gene-specific primers (Table 1) were designed to contain $E c o$ RV and EcoRI recognition sites. The PnOLPl open reading frame (ORF) without the stop codon was obtained by PCR using cDNA reverse-transcribed from RNA of $P$. notoginseng roots. The ORF was subcloned into a pBIN m-gfp5-ER vector, and the recombinant vector was transformed into Agrobacterium tumefaciens EHA105. The Agrobacterium tumefaciens harboring the pBIN m-gfp5-ER-PnOLP1 plasmids were obtained by PCR and used to the transiently express in onion epidermal cells. The transformed onion epidermal cells were incubated for 2 days on the coculture medium, and then the PnOLP1GFP fusion protein was localized using a laser scanning confocal microscope (Nikon A1R, Japan). The detailed protocol was published previously in Liu et al. (2018).

Expression and purification of the recombinant PnOLP1 protein. Gene-specific primers (Table 1) were designed to amplify

TABLE 1. The gene-specific primers

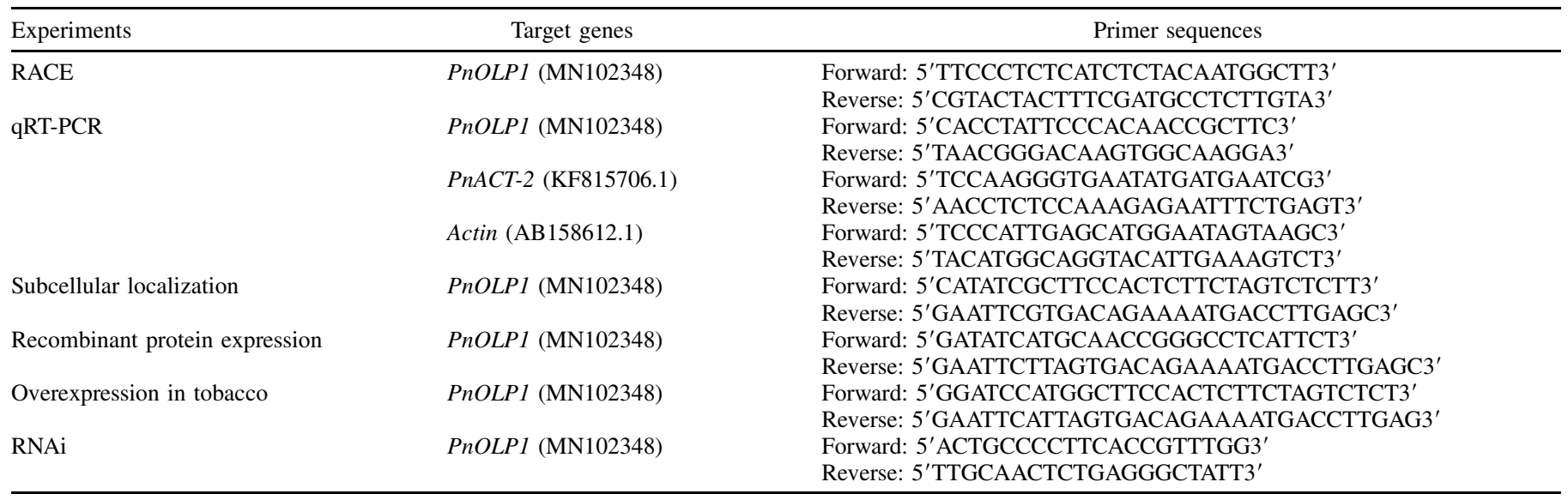


the PnOLPl ORF without the $5^{\prime}$ terminus that encodes the secretion signal peptide. The truncated $P n O L P l$ was then inserted into the multiple cloning site of the $\mathrm{pET}-32$ (a) vector. The recombinant $\mathrm{pET}$ 32(a)-PnOLP1 plasmids were further transformed into Escherichia coli $\mathrm{BL} 21$ (DE3) to express the recombinant protein containing a Nterminal His-tag. The positive clones were incubated in LB broth medium in the presence of ampicillin. Following incubation at $37^{\circ} \mathrm{C}$ until an optical density reading of 0.6 to 0.8 at $600 \mathrm{~nm}$, the recombinant E.coli BL21 were placed on ice for $30 \mathrm{~min}$, and then they were incubated with isopropyl $\beta$-D-thiogalactoside at $1 \mathrm{mmol} /$ liter for $7 \mathrm{~h}$ at $25^{\circ} \mathrm{C}$ to induce the protein. The PnOLP1 protein was expressed in the inclusion bodies. An inclusion body solubilizing solution (50 mM Tris- $\mathrm{HCl}, \mathrm{pH} 8.8,300 \mathrm{mM} \mathrm{NaCl}$, and $8 \mathrm{M}$ urea) was added to the pellet, and the sample was incubated on a shaker (room temperature at $220 \mathrm{rpm}$ ) for $1.5 \mathrm{~h}$ to denature the protein. The supernatant and precipitate were collected after centrifugation $\left(4^{\circ} \mathrm{C}\right.$ at $10,000 \mathrm{rpm}$ for $30 \mathrm{~min}$ ). The denatured recombinant protein in the supernatant was purified using a Ni-NTA-Sepharose column (Sangon Biotech, China). The denatured protein was subjected to dialysis renaturation through a dialysis bag, and the target protein was concentrated using a Millipore ultrafiltration tube $(10 \mathrm{kD})$ having a molecular weight cut-off for the His-PnOLP1 fusion protein of $1 / 6$ to $1 / 3$. The concentrated recombinant protein was used for the in vitro antifungal activity analysis.

In vitro antifungal assay of the recombinant PnOLP1 protein. F. oxysporum, $F$. graminearum, and $F$. solani hyphae were inoculated on PDA medium and cultured at $28^{\circ} \mathrm{C}$ for 2 to 3 days. Then the sterile filter paper ( $6 \mathrm{~mm}$ in diameter) was placed evenly on the edge of the colony, and 5, 10, and $15 \mu \mathrm{g}$ of recombinant PnOLP1 protein solution was placed sequentially on the filter paper. The amount of the recombinant protein was measured with the Bradford method using a Bradford Protein Assay Kit (Sangon Biotech, China). The negative controls were the sterile water and phosphate buffer ( $\mathrm{pH} 8.0)$. After the fungi were incubated at $28^{\circ} \mathrm{C}$ for 2 to 3 days, the growth states of the three pathogenic fungal hyphae were recorded. The zones of fungal growth inhibition around the disks were measured using Adobe Photoshop version 7.0, and the antifungal assay was repeated three times.

Generation and selection of PnOLP1 transgenic tobacco. The PnOLPI ORF was obtained using gene-specific primers (Table 1) and then ligated into the pGEM-T vector. The pGEM-T-PnOLP1 vector and the plant expression vector pCAMBIA2300s were digested with restriction endonucleases EcoRI and BamHI, respectively, and then the gel-recovered fragments were ligated using T4 DNA ligase. The ligated product was transferred into $E$. coli $\mathrm{DH} 5 \alpha$, and the positive clones containing pCAMBIA2300s- $P n O L P 1$ were screened by PCR. The pCAMBIA2300s-PnOLP1 recombinant vector was transferred into Agrobacterium tumefaciens LBA4404 using the freeze-thaw method, and then the positive clones were obtained by PCR. The pCAMBIA2300s-PnOLP1 plasmids in Agrobacterium tumefaciens LBA4404 were transferred into WT tobaccos by the tobacco leaf disc method. The methods of screening transgenic tobacco and obtaining T2 transgenic tobacco were similar to those of Liu et al. (2018).

Resistance identification of the $\mathrm{T} 2$ generation of transgenic tobacco. The qRT-PCR was used to assess the transcription levels of PnOLP1 in the T2 tobacco lines, and the reference gene was the tobacco actin gene (AB158612.1) (Table 1). In addition, the three lines of $\mathrm{T} 2$ transgenic tobacco with high $P n O L P 1$ expression levels were selected for to determine their resistance to $F$. solani infection. The same size wounds were gently created on the tobacco leaves with sandpaper, and $100 \mu \mathrm{l}$ of $F$. solani spore suspension $(2 \times$ $10^{6}$ spores $/ \mathrm{ml}$ ) was inoculated on the wound sites. All the inoculated leaves were placed on wet filter paper to maintain moisture and cultured in a light incubator $\left(25^{\circ} \mathrm{C}, 16-\mathrm{h}\right.$ light/day). After incubating for 7 days, the disease symptoms were recorded with a digital camera (Canon, Japan). Additionally, sterile WT tobacco and PnOLPI transgenic tobacco plants of a uniform size were selected to receive the
F. solani inoculations. The tobacco roots were wounded with scissors, and the treated tobacco roots were immersed in a spore suspension $(2 \times$ $10^{6}$ spores $\left./ \mathrm{ml}\right)$. The inoculated tobacco plants were cultured for 12 days in a light incubator, and the disease symptoms were recorded using the digital camera. The inoculation experiment was repeated three times.

Transient expression PnOLP1 RNAi construct in $P$. notoginseng leaves. The $P n O L P 1$-specific primers with attB adapter (Table 1) were designed to amplify the RNAi fragment (520 bp). A Gateway BP Clonase II Enzyme Mix (Invitrogen, U.S.A.) was used to perform a recombination reaction between the PnOLP1 RNAi PCR product and the pHellsgate2 vector, and then the $\mathrm{BP}$ reaction mixture was transformed into the E. coli $\mathrm{DH} 10 \mathrm{~B}$. The pHellsgate2-PnOLP1 recombinant plasmids were further transformed into Agrobacterium tumefaciens LBA4404, and the positive clones were identified by PCR, which were used to infect the $P$. notoginseng leaves.

The same size wounds were gently created on the healthy $P$. notoginseng leaves with sand paper, and then the leaves placed on the damp filter paper. The Agrobacterium tumefaciens suspension $(50 \mu \mathrm{l})$ containing the pHellsgate2-PnOLP1 recombinant plasmid was added to the wound sites, and the infected leaves were cultured in a light incubator for 24-h in order to transiently express the PnOLP1 RNAi construct in $P$. notoginseng leaves. In addition, the infection with nontransformation Agrobacterium tumefaciens suspension was performed with the same method as a control. The infected leaves were further inoculated with $F$. solani spore suspension $\left(2 \times 10^{6} \mathrm{spores} / \mathrm{ml}\right)$ at the wound sites, and then were cultured in a light incubator $\left(25^{\circ} \mathrm{C}, 16-\mathrm{h}\right.$ light/day). The disease symptoms of $P$. notoginseng leaves were recorded using the digital camera after $72 \mathrm{~h}$, and the leaves were collected and frozen in liquid nitrogen for RNA extraction. The $P n O L P 1$ expression level in $P$. notoginseng leaves after transient expression of PnOLP1 RNAi construct was analyzed by qRT-PCR.

Statistical analyses. The transcription levels of PnOLPl in $P$. notoginseng and $\mathrm{T} 2$ tobacco lines, lesion size caused by $F$. solani infection as well as the fungal growth inhibition zones, are shown as means with standard deviations. Student's $t$ test was performed using SPSS software to reveal the statistical differences between the treatments or inoculations and the controls.

\section{RESULTS}

Molecular cloning and bioinformatics analysis of PnOLP1. In this study, an OLP gene, PnOLPl (GenBank accession number MN102348), was isolated from $P$. notoginseng. The PnOLP1 cDNA was $1,098 \mathrm{bp}$, and it contained an ORF of $744 \mathrm{bp}$, a $5^{\prime}$ untranslated region (UTR) of $43 \mathrm{bp}$, and a 3' UTR of 311 bp. PnOLPl encoded a protein of 247 amino acid residues with a calculated molecular mass of $26.4 \mathrm{kDa}$ and theoretical isoelectric point of 7.21. PredictProtein predicted the protein to have a signal peptide of 22 amino acid residues at the N-terminus, and it was predicted to be a secreted protein. The mature PnOLP1 was predicted to have 225 amino acid residues with a calculated molecular mass of $24.1 \mathrm{kDa}$ and theoretical isoelectric point of 7.31. PredictProtein predicted the secondary structure of the PnOLP1 protein to contain an $\alpha$-helix, $\beta$-sheet, and random coil, with percentages of $9.72,15.79$, and $74.49 \%$, respectively. Moreover, there may be 8 disulfide bonds in PnOLP1 protein structure according to the bioinformatics prediction result with PROSITE. The deduced PnOLP1 protein was highly homologous with known plant OLPs, and it shared an 82,78, and 79\% identity with Quercus suber (XP_023907784.1), Ziziphus jujuba (NP_001310784.1), and Erythranthe guttata (XP_012827362.1) OLPs, respectively.

In addition, a phylogenetic tree of 20 plant OLPs and osmotins was constructed, that consists of two big branches (Fig. 1). The upper branch is composed of PnOLP1 and 11 homologous OLPs from different species, which is clearly divided into two groups. The OLPs from Brachypodium distachyon (XP_003564582.1), 
Hordeum vulgare (BAK00635.1), Zea mays (NP_001147098.2), Oryza sativa Japonica group (BAG87528.1), and $O$. sativa Indica group (ADI43216.1) fall into the monocotyledonous group. The dicotyledonous group contains seven OLPs from E. guttata (XP_012827362.1), Gossypium raimondii (XP_012446484.1), G. hirsutum (XP_016750563.1), Herrania umbratica (XP_ 021278215.1), Z. jujuba (NP_001310784.1), Q. suber (XP_ 023907784.1), and $P$. notoginseng, respectively. The lower branch consists of six OLPs and two osmotins that have been reported to be involved in defense response to stress.

PnOLP1 responded to several signaling molecule treatments and was up-regulated during $F$. solani infection. The PnOLP1 expression level in $P$. notoginseng roots was induced by MeJA, ETH, $\mathrm{H}_{2} \mathrm{O}_{2}$, and SA treatments (Fig. 2A to D). Compared with the control, the MeJA treatment rapidly induced the expression of $\mathrm{PnOLPl}$, reaching the maximum level at $4 \mathrm{~h}$. For the ETH, $\mathrm{H}_{2} \mathrm{O}_{2}$, and SA treatments, the highest $P n O L P 1$ expression levels were reached at $48 \mathrm{~h}$. Our previous study indicated that a pretreatment with MeJA increased the resistance of $P$. notoginseng to $F$. solani infection, and based on the qRT-PCR analysis in the present study, the transcriptional level of PnOLP1 was higher in the MeJA-pretreated $P$. notoginseng roots during $F$. solani infection than in the sterile waterpretreated roots (Fig. 2E). The maximum PnOLP1 expression was recorded at 48-h postinfection in the $P$. notoginseng roots pretreated with MeJA, and the relative gene expression value was roughly 2.8 times as much as the control (sterile water-pretreated without inoculation). In brief, the four signaling molecules induced the expression level of PnOLP1 in P. notoginseng roots, and the MeJApretreatment greatly up-regulated $P n O L P 1$ expression during $F$. solani infection. These data indicated that PnOLPl is involved in $P$. notoginseng defense responses against $F$. solani.

PnOLP1 protein is localized in the plant cell wall. It was predicted that the protein PnOLP1 was localized on the plant cell wall. Agrobacterium tumefaciens containing the PnOLP1-GFP fusion gene was used to transform onion epidermal cells to confirm the localization of PnOLP1. The green fluorescence in the onion cells transformed with the PnOLP1-GFP was specifically distributed on the cell wall (Fig. 3). In contrast, the green fluorescence of the empty vector was uniformly distributed throughout the onion epidermal cells. Thus, PnOLP1 is localized in the plant cell wall.

The recombinant PnOLP1 protein expressed in $E$. coli possesses antifungal activities to $P$. notoginseng root rot disease pathogens. A truncated form of PnOLP lacking the secretory signal sequence was cloned into the prokaryotic expression vector $\mathrm{pET} 32 \mathrm{a}$ and heterologously expressed in E. coli to obtain a recombinant PnOLP1 protein. The E. coli BL21 cells with pET32a-PnOLP1 were induced with isopropyl $\beta$-Dthiogalactoside at $1 \mathrm{mmol} /$ liter for $7 \mathrm{~h}$ at $25^{\circ} \mathrm{C}$, and the SDSPAGE analysis indicated that large amount of recombinant protein with approximately $40 \mathrm{kDa}$ molecular mass was induced

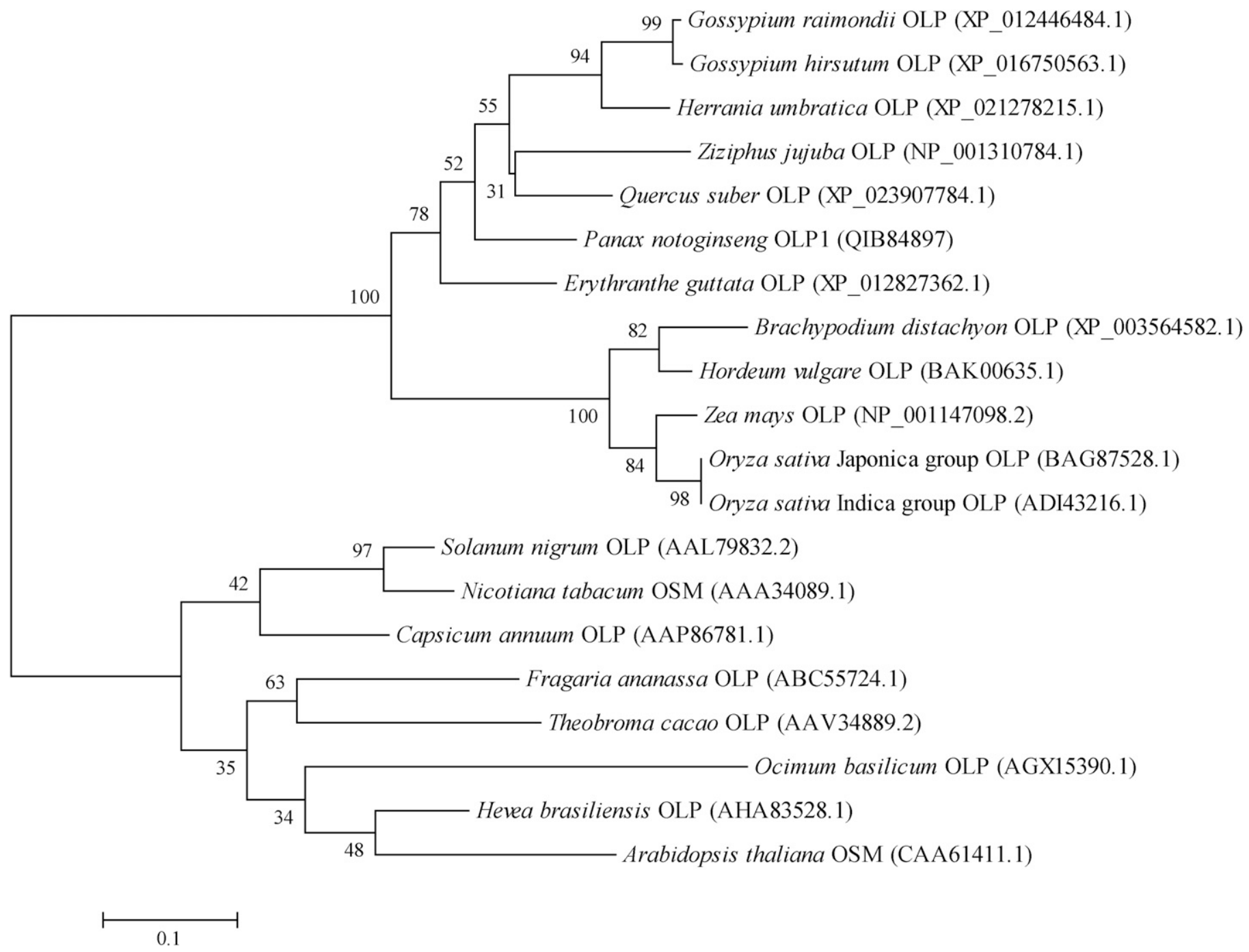

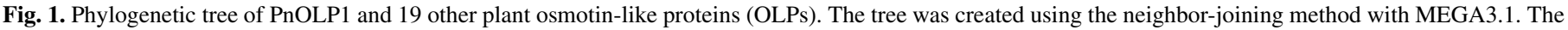
scale bar equals a distance of 10 changes per 100 amino acid positions, and the numbers on each node represent bootstrap values of 1,000 replicates. 
(Supplementary Fig. S1a). The Ni-NTA column was used to bind the PnOLP1 recombinant protein, and then the purified protein was eluted with $100 \mathrm{mM}$ imidazole elution buffer (Supplementary Fig. S1b). Furthermore, the antifungal assay showed that the PnOLP1 recombinant protein inhibited the mycelial growth of the $P$. notoginseng root rot disease-related pathogens $F$. oxysporum, $F$. solani, and F. graminearum (Fig. 4A to C). Compared with the blank control (sterile water), the fungal growth inhibition scores produced by 5,10 , and $15 \mu \mathrm{g} / \mathrm{ml}$ of recombinant PnOLP1 protein against $F$. oxysporum were $23.92,28.44$, and $63.14 \mathrm{~mm}^{2}$, respectively (Fig. 4D). The inhibition scores for the same amounts of protein against $F$. solani were $20.58,33.03$, and $51.02 \mathrm{~mm}^{2}$, respectively, while they were 29.06, 37.89, and $64.81 \mathrm{~mm}^{2}$, respectively, against $F$. graminearum (Fig. 4D). Thus, the PnOLP1 recombinant protein had the strongest inhibitory activity against the mycelial growth of $F$. graminearum, and the antifungal activities increased along with the recombinant PnOLP1 protein level.

Overexpression of $P$ OLPI conferred a high level of resistance to $F$. solani infection. To further understand the biological function of $P n O L P 1$, the plant overexpression vector pCAMBIA2300s-PnOLPl was constructed, and more than 100 tobacco leaf discs were transformed by Agrobacterium tumefaciens. A total of $45 \mathrm{~T} 0$ transgenic tobacco plants were screened using PCR with PnOLPl-specific primers. In addition, 12
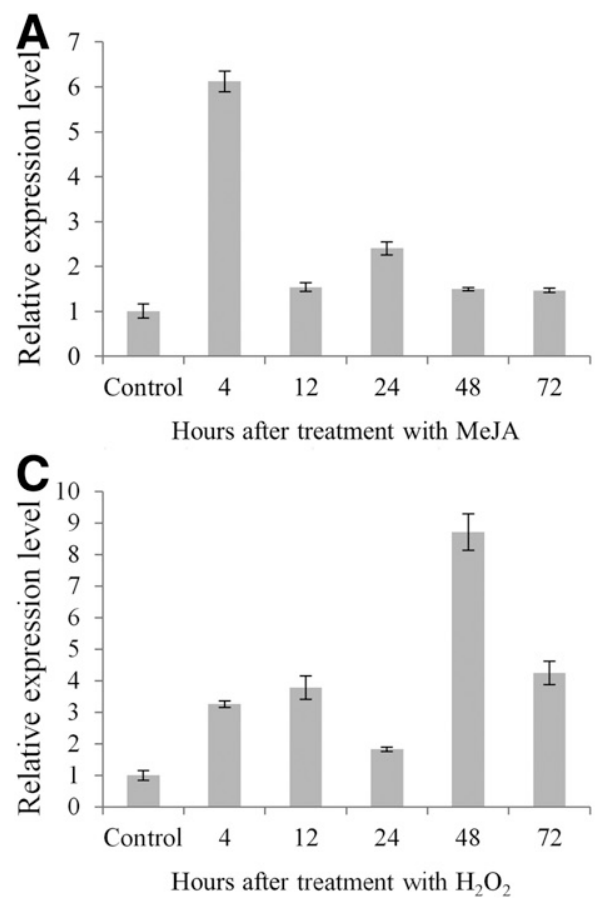

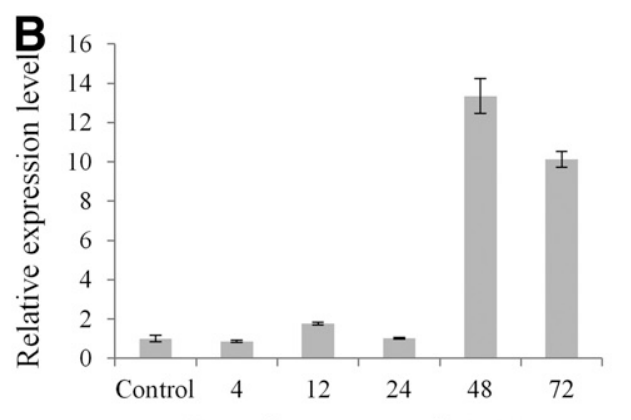

Hours after treatment with ETH

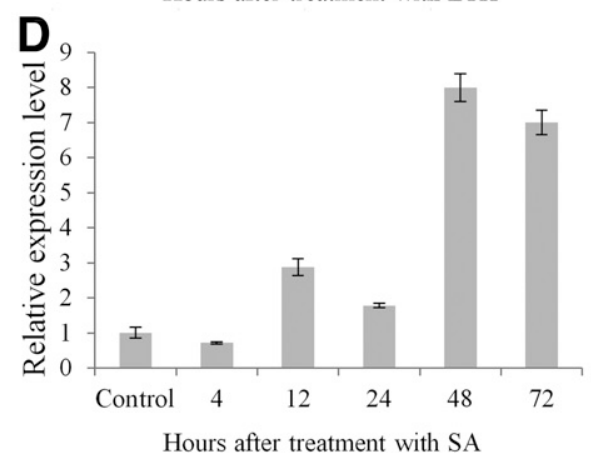

$\mathbf{E}$

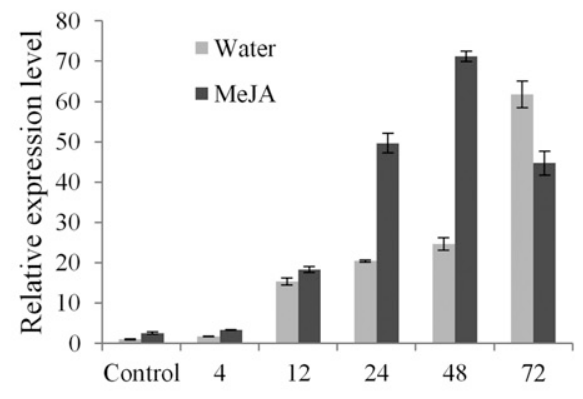

Hours post inoculation with $F$. solani

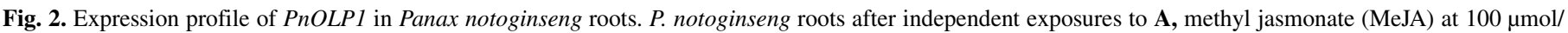

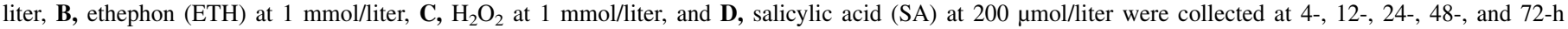

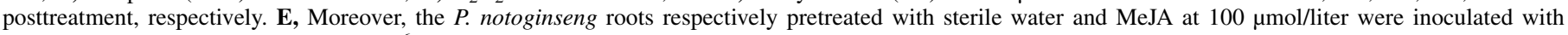

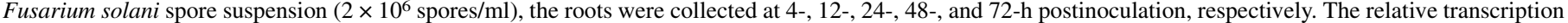
levels of PnOLP1 were assessed by qRT-PCR, and the results are shown as the average values calculated from three replicates.
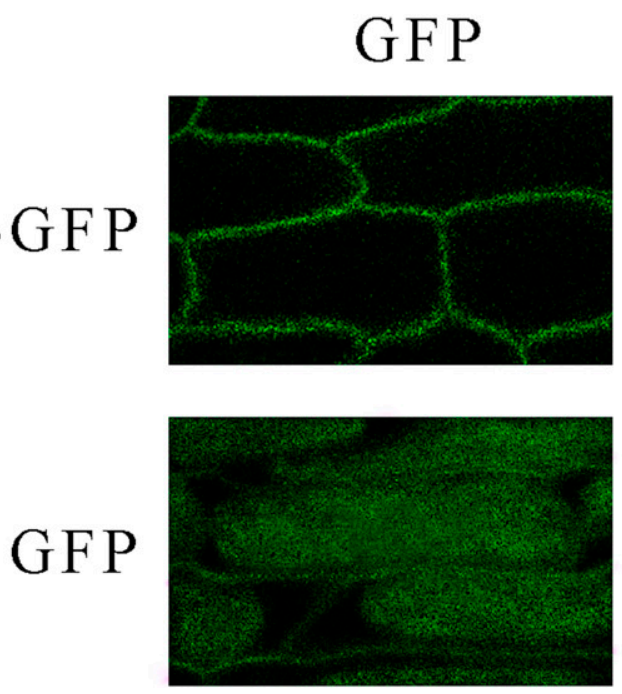

Bright
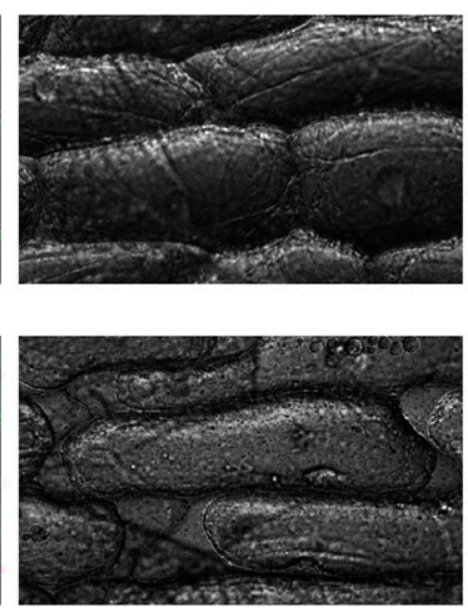

Merged
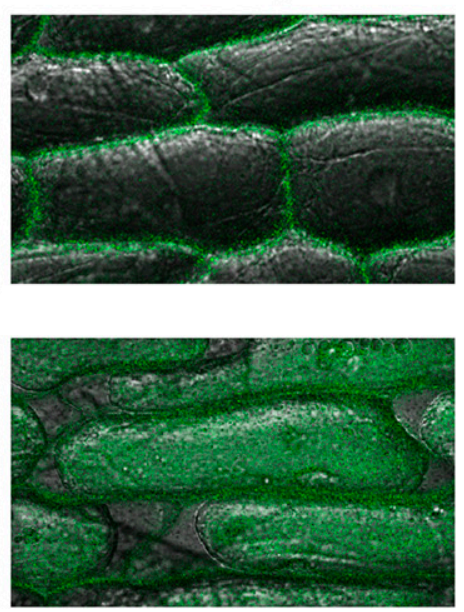

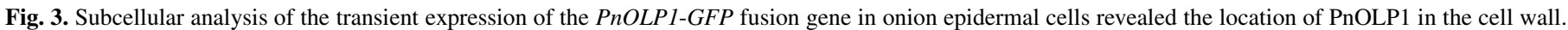

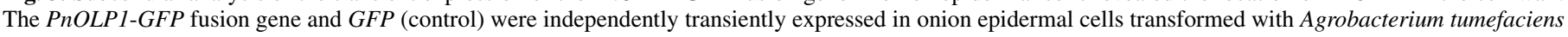

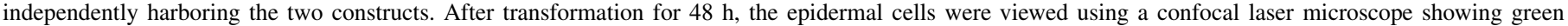
fluorescence (GFP), bright field illumination (bright), and combined (merged) views. 
transgenic tobacco plants were randomly selected to develop the T2 transgenic tobacco lines $(\mathrm{O} 2, \mathrm{O} 5, \mathrm{O} 6, \mathrm{O} 7, \mathrm{O} 13, \mathrm{O} 16, \mathrm{O} 19, \mathrm{O} 20$, $\mathrm{O} 22, \mathrm{O} 25, \mathrm{O} 26$, and O33). The qRT-PCR analysis indicated that PnOLP1 was overexpressed in all the transgenic lines (Fig. 5A). The CaMV 35S promoter of the overexpression vector directed the stable expression of PnOLP1 in the transgenic plants. Based on the qRT-PCR, the tobacco lines O2, O6, and O7, having high PnOLP1 expression levels, were selected for further study.

To evaluate the resistance levels of PnOLP1 transgenic tobacco, the young leaves of three transgenic tobacco lines and WT tobacco were inoculated with $F$. solani spore suspensions at wound sites. After 7 days of inoculation, the leaves of the transgenic lines showed slight decaying and yellowing around the inoculation sites (Fig. 5B), while more evident yellowing and rot, over an area of $300 \mathrm{~mm}^{2}$, was presented in the WT tobacco leaves (Fig. 5C). In addition, the roots of WT and transgenic tobacco seedlings were inoculated with F. solani, and the disease symptoms are shown in Figure 5D. The roots of WT tobacco were severely blackened, rotted, and easily detached. Additionally, whole leaves withered, and the stems and leaves near the roots turned yellow and rotten. However, the transgenic lines showed mild symptom, such as a slight blackening of roots, and they grew normally (Fig. 5D). Thus, the overexpression of PnOLPl in tobacco enhanced its resistance to $F$. solani infection.

Transient expression of PnOLP1 RNAi vector in $P$. notoginseng leaves increased susceptibility to $F$. solani. The stable genetic transformation system for $P$. notoginseng is not established so far, therefore, the PnOLP1 RNAi construct was transiently expressed in the $P$. notoginseng leaves in order to analyze its function. The PnOLP1 RNAi construct was expressed in the leaves mediated by Agrobacterium tumefaciens, which was followed by the $F$. solani inoculation. The result indicated that both the PnOLPl RNAi construct expressed leaves and the control leaves showed evident rot after inoculation with $F$. solani; however, the lesion
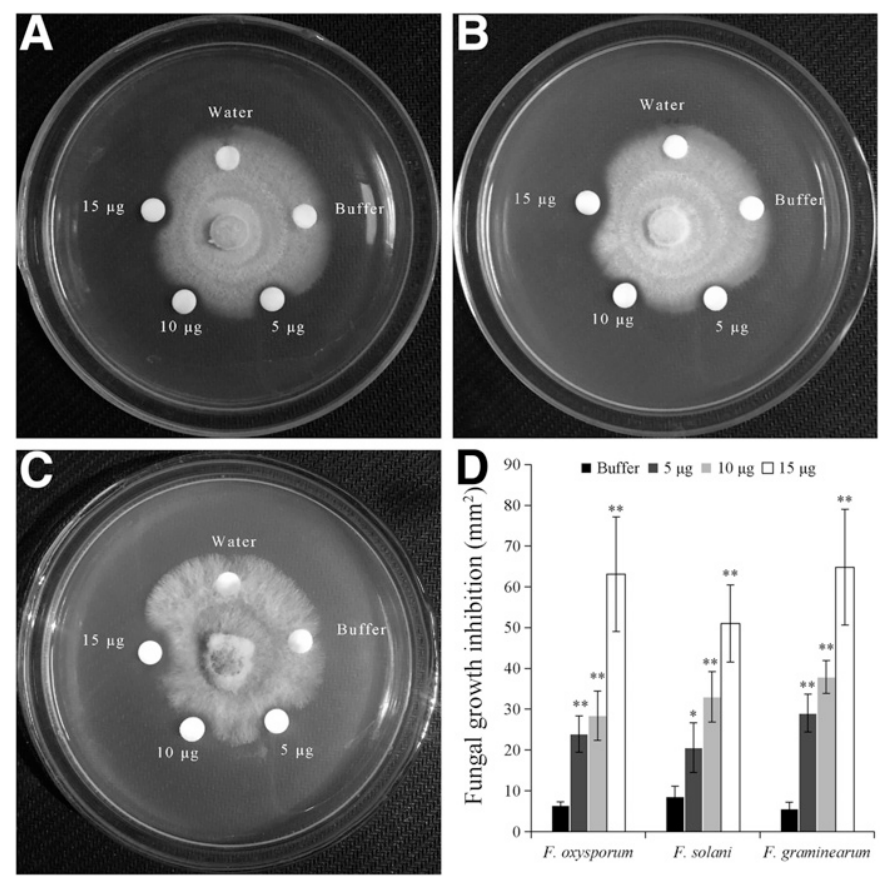

Fig. 4. Antifungal assay using the recombinant PnOLP1 protein. The recombinant PnOLP1 protein has evident antifungal activities to A, Fusarium oxysporum, B, F. solani, and C, F. graminearum. Water and phosphate buffer $(\mathrm{pH} 8.0)$ are the negative controls. D, In addition, the fungal growth inhibition analysis showed that the antifungal activities increased along with the recombinant PnOLP1 protein level. Results are shown as the average values calculated from three replicates, and the Student's $t$ test was used to analyze the statistical differences between the recombinant PnOLP1 protein and the negative control (** $P<0.01$, * $P<0.05$ ). size of the PnOLPl RNAi construct transiently expressed $P$. notoginseng leaves was significantly bigger than that of control (Fig. 6A and B). Furthermore, the qRT-PCR showed that the PnOLP1 expression level in $P$. notoginseng leaves expressing the PnOLP1 RNAi construct was about 2.2 times lower than that of the control after inoculation with $F$. solani for $72 \mathrm{~h}$ (Fig. 6C). It is evident that the decreased PnOLP1 expression level in $P$. notoginseng leaves increased the susceptibility to $F$. solani infection.

\section{DISCUSSION}

Osmotins and OLPs belong to the PR5 family, and they play important roles in the plant defense system against a variety of biotic and abiotic stresses (Cao et al. 2015; Hakim et al. 2018). In this study, an $O L P$ gene was isolated from the famous Chinese medicinal plant $P$. notoginseng. The deduced PnOLP1 protein has a signal peptide at the N-terminus like some osmotins and OLPs from S. dulcamara, Hordeum vulgare, and Hevea brasiliensis (Newton and Duman 2000; Reiss et al. 2006; Tong et al. 2016). In addition, the proteins in the PR5 family, including TLPs and osmotins, are cysteine-rich proteins. For example, barley TLP 1-8 has 10 or 16 cysteine residues (Reiss et al. 2006). A total of 17 cysteine residues are distributed in the PnOLP1 protein sequence, and the bioinformatics prediction result showed that these cysteine residues may form 8 disulfide bonds, that could provide stability to the protein under adverse environmental conditions.

The secretory proteins are conventionally transported through the endoplasmic reticulum to the Golgi and then to the plasma membrane where they are released into the extracellular space (Rabouille 2017). The PnOLP1 was predicted to be a secreted protein and localized on the cell wall in this study, and the subcellular localization result supported the prediction by showing that PnOLP1 is distributed in the onion epidermal cell wall. Glycine max OLPa protein with a predicted $\mathrm{N}$-terminal signal peptide is secreted into the extracellular matrix, while GmOLPb protein with a $\mathrm{N}$-terminal signal peptide and the $\mathrm{C}$-terminal vacuolar target peptide is secreted into the vacuolar compartment (Onishi et al. 2006; Tachi et al. 2009). The CAOSMI mRNA is prevalently localized in the phloem cells of vascular bundles in pepper leaf, however, the subcellular localization indicates that CAOSM1 protein is localized in the plasma membrane of $N$. benthamiana leaf cells (Choi et al. 2013; Hong et al. 2004). In addition, HbOsmotin protein from the latex of Hevea brasiliensis is mainly distributed in the lutoid fraction of latex, and the subcellular localization indicates that the protein is distributed in the cell wall of onion epidermal cells (Tong et al. 2016). HbOsmotin primarily remains in the lutoid, moreover, it could be secreted by protoplasts. The plant cell wall is the first obstacle for pathogens to penetrate and infect the plant cells, and it is also a sensor for pathogen invasion. The plant cells recruit their own cell surface pattern recognition receptors to identify the pathogen-associated molecular patterns (PAMP) during pathogen infection (Boller and $\mathrm{He} 2009$ ), meanwhile, some cell wall proteins show evident antimicrobial activity (Bellincampi et al. 2014). Although the diversified localizations of plant OLP proteins may be associated with their different functions in plant cells, the cell wall-localized PnOLP1 protein may act as a defense protein that interacts with invading pathogens during the early stage of infection.

$P$. notoginseng is a highly valued medicinal plant in China, but the root rot seriously impairs the production and quality of $P$. notoginseng raw material. Our previous study indicated that exogenous application of MeJA on roots of $P$. notoginseng induced a high level of resistance to the root rot pathogen $F$. solani (Liu et al. 2019). Many genes involved in the plant-pathogen interactions were predominantly up-regulated by MeJA; moreover, these genes showed increased transcriptional levels after inoculation with F. solani. This study clearly showed that the PnOLPl is a defense related genes responding to the exogenous application of MeJA, 
which hints that the $P n O L P l$ is regulated by the JA signaling during defense to $F$. solani infection. In addition, some phytohormone signaling pathways including the ETH and SA are important parts of signal transduction in the plant immune response, and the crosstalk among these different signaling pathways is ubiquitous (Vos et al. 2015). The gene expression pattern analysis indicated that the PnOLPl expression was induced by the SA and ETH treatments. Similarly, the exogenous MeJA/ETH also significantly induced the expression of $O L P$ gene from Ocimum basilicum and the osmotin gene SINP24 from germinated tomato seeds (Pluskota et al. 2019; Rather et al. 2015). Furthermore, the transcriptome sequencing data showed that the SA and ETH signaling pathwayrelated genes were positively regulated in the MeJA treated $P$. notoginseng during response to $F$. solani (Liu et al. 2019),

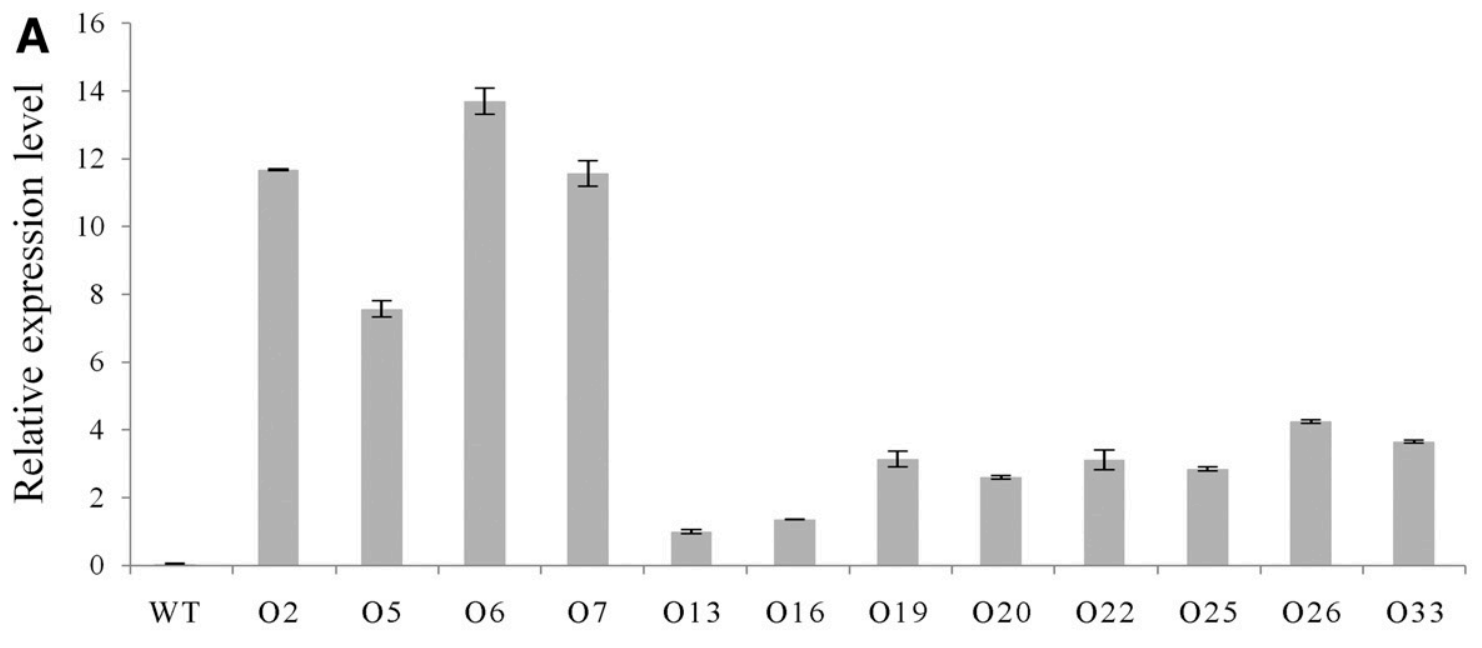

B
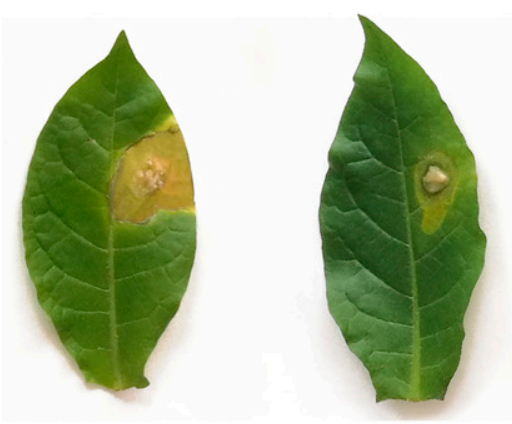

$\mathrm{O} 2$

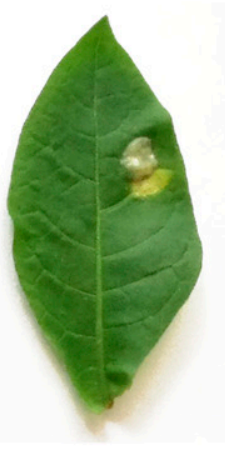

06
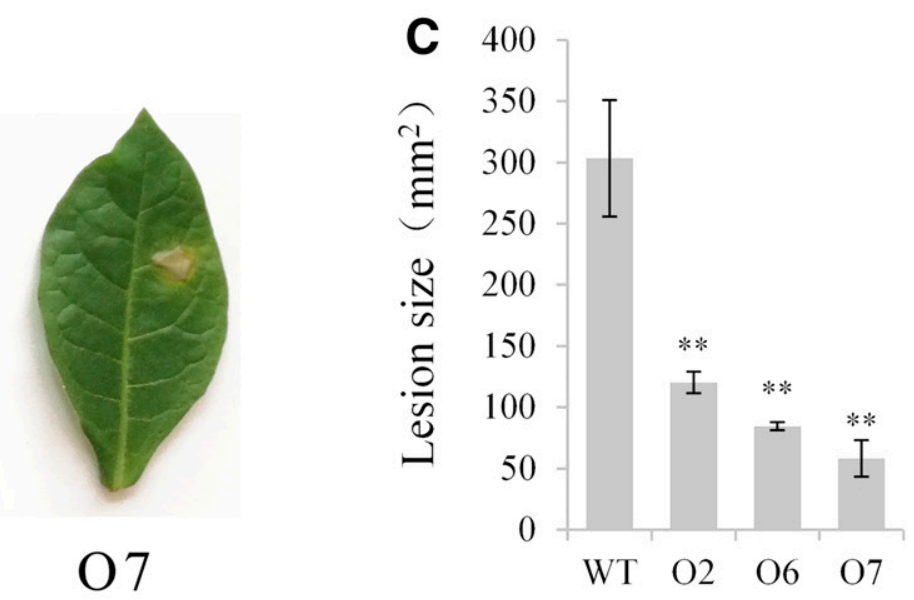

D

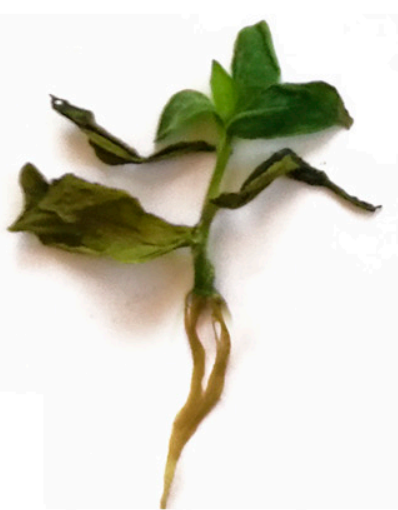

WT

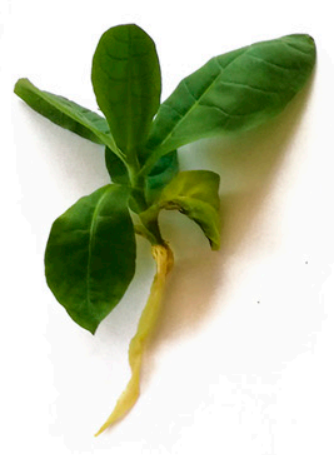

$\mathrm{O} 2$

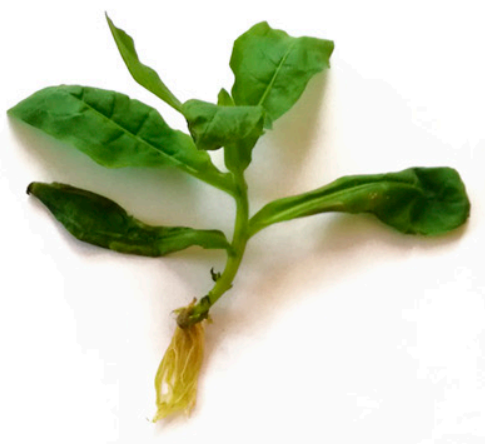

O 6

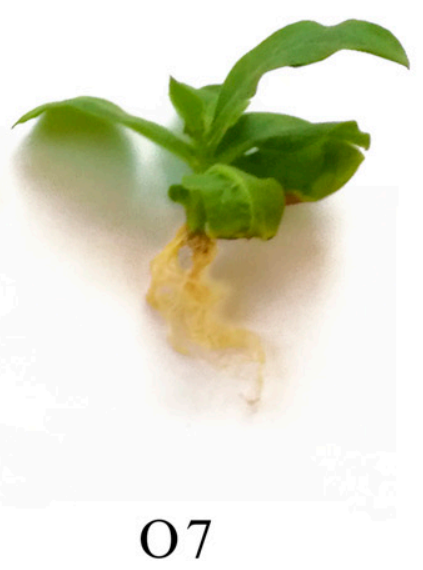

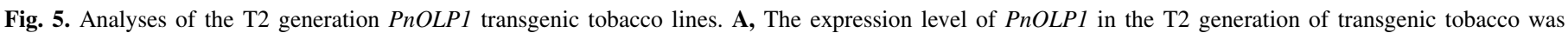

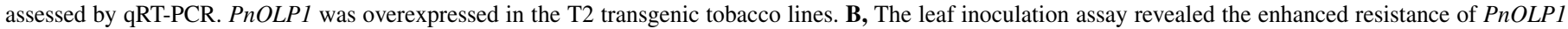

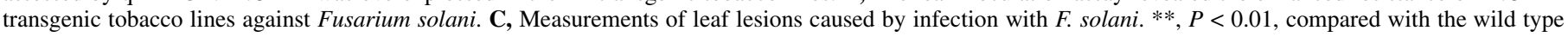

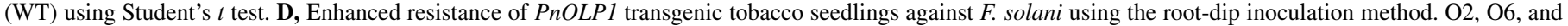
O7 represent transgenic tobacco lines. 
suggesting that the crosstalk among JA, SA, and ETH signaling pathways is present in the immune reaction to $F$. solani. The molecular mechanism of the PnOLP1 regulated by the hormone signaling pathways needs to be further explored.

In order to escape the PAMP recognition of plant defense system, pathogens produce the effector proteins that counteract the plant defense responses, meanwhile, the antimicrobial proteins that are the final effectors of plant defense can recognize the pathogen effectors (Giraldo and Valent 2013; Lee et al. 2010). Studies have shown the specific interaction between osmotin and pathogenic plasma membrane, and the osmotin protein is an ultimate effector of plant defense with antifungal activity (Narasimhan et al. 2001, 2005). There is a potential target position of osmotin in the fungal membrane, and when the osmotin reacts with the fungal wall, it allows the osmotin to enter the plasma membrane, which in turn leads to the formation of transmembrane pores and rupture of the fungal membrane (Anžlovar and Dermastia 2003; Hakim et al. 2018; Singh et al. 2013). Moreover, the conserved fungal genes including the FOR1 (Fusarium Osmotin Resistance), FOR2, and $F O R 3$ that determine the cell wall characteristics play an important role in regulating the sensitivity of fungi to plant defense protein osmotin (Lee et al. 2010). This may be the reason why the fungi show different sensitivity to the different plant antimicrobial proteins. The OLP protein purified from Calotropis procera latex has strong antifungal activity against $F$. solani and smaller activity against Colletotrichum gloeosporioides (de Freitas et al. 2011b). This study confirmed that the protein encoded by the PnOLPl gene is an antifungal protein, moreover, the heterologously expressed PnOLP1 recombinant protein in E. coli inhibited the mycelial

A

PnOLPI RNAi
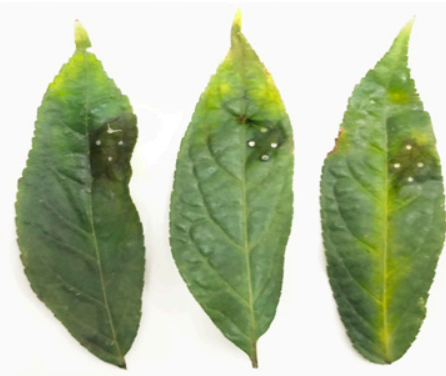

B
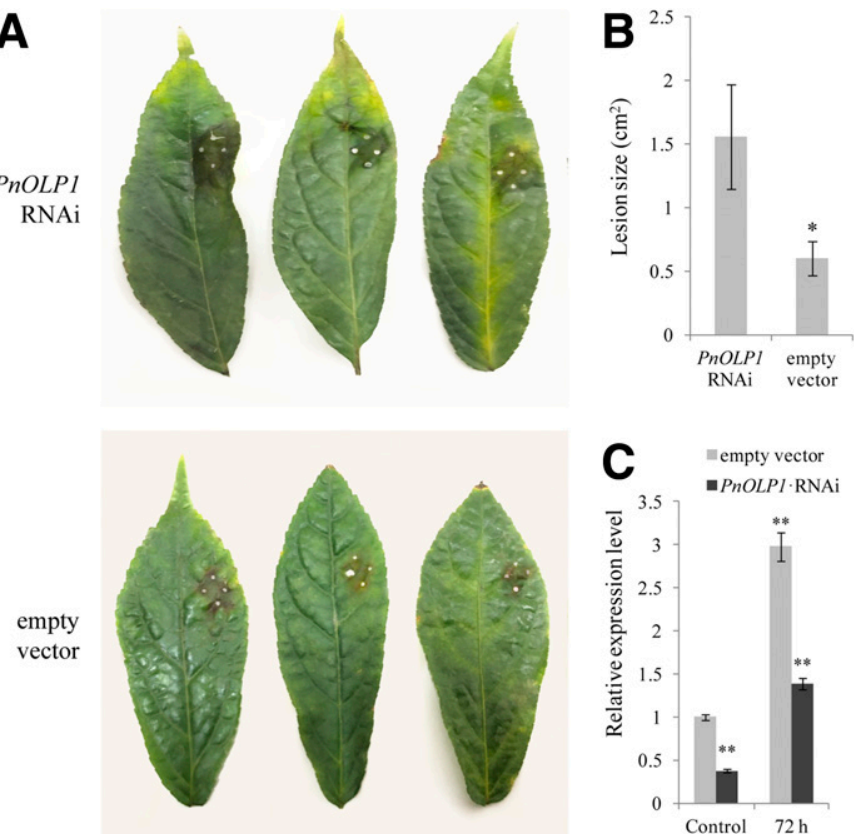

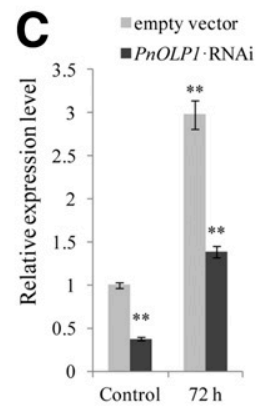

Fig. 6. Analysis of Panax notoginseng leaves after transient expressing the PnOLP1 RNAi construct. A, Inoculation experiments showed that the transient expression of $P n O L P 1$ RNAi construct in the $P$. notoginseng leaves increased the susceptibility to Fusarium solani infection compared with the control (the $P$. notoginseng leaves transiently expressing the empty RNAi vector after inoculation with $F$. solani for $72 \mathrm{~h}$ ). B, Measurements of leaf lesions caused by $F$. solani infection. The Student's $t$ test was used to analyze the statistical difference $(*, P<0.05)$. C, The expression level of $P n O L P 1$ in the $P$. notoginseng leaves transiently expressing the $P n O L P 1$ RNAi construct evaluated by qRTPCR. Control, the P. notoginseng leaves infected with Agrobacterium tumefaciens suspension containing the pHellsgate2-PnOLP1 and pHellsgate2 empty vector, respectively; and $72 \mathrm{~h}$, two control samples were inoculated with $F$. solani for $72 \mathrm{~h}$. Results are shown as the average values calculated from three replicates, and the Student's $t$ test was used to analyze the statistical differences (** $P<0.01$ ). The empty RNAi vector infected samples without inoculation with $F$. solani was the control of statistical analysis. growth of $F$. oxysporum, $F$. graminearum, and $F$. solani with small difference in activity. All these three Fusarium pathogens not only harm the $P$. notoginseng growth and development, but also threaten the quality of original medicinal materials. The high level of antifungal activity against the three Fusarium pathogens hints that the PnOLP1 maybe directly interacts with the root rot pathogens as a cell wall defense protein.

Furthermore, the reverse genetics technology was used to verify the function of PnOLPl in this study. The transgenic tobacco expressing the PnOLPl showed strong resistance to $F$. solani. In addition, the gene silencing was induced by the RNAi vector of $P n O L P 1$ through transient expression in the P. notoginseng leaves, and the reduced $P n O L P 1$ expression increased the susceptibility to $F$. solani infection. These data clearly indicate that $P n O L P l$ is an important resistance gene in the defense responses of $P$. notoginseng. Fusarium disease is well known to be an important factor, which causes heavy agricultural losses, and the PnOLPl can be transferred into the food and economic plants in order to develop the genetically modified plants with a high level of resistance to Fusarium pathogens. The transgenic potato plants expressing an OLP gene ( $p A 13)$ showed increased resistance to the Phytophthora infestans (Sanju et al. 2015). The S. nigrum OLP and rice Chill were transferred into tomato, and the resistance against Alternaria solani and $F$. oxysporum was increased (Kumar et al. 2016). Moreover, the transgenic rice lines expressing the tobacco osmotin gene exhibited a high level of resistance to sheath blight (Rhizoctonia solani) (Sripriya et al. 2017). Additionally, there is hope in developing the transgenic plants with broadspectrum resistance to a variety of different pathogens by cotransformation of PnOLPl and other reported disease resistance genes.

Conclusion. This is the first report on $O L P$ gene characterization from $P$. notoginseng. The antifungal activity in vitro suggests that the PnOLP1 protein directly participates in the defense process against the infection of $P$. notoginseng root rot pathogen. Moreover, the $P n O L P 1$ gene plays an important role in $P$. notoginseng defense response mediated by the JA signaling pathway during $F$. solani infection, in which the SA and ETH signaling pathways may crosstalk the JA signaling in modulating the $P n O L P 1$ expression. In addition, PnOLP1 is a new candidate gene for plant diseaseresistant genetic engineering.

\section{ACKNOWLEDGMENTS}

We thank Lesley Benyon, Ph.D., from Liwen Bianji, Edanz Group China (http://www.liwenbianji.cn/ac), for editing the English text of a draft of this manuscript.

\section{LITERATURE CITED}

Anžlovar, S., and Dermastia, M. 2003. The comparative analysis of osmotins and osmotin-like PR-5 proteins. Plant Biol. 5:116-124.

Baichoo, Z., and Jaufeerally-Fakim, Y. 2017. Ralstonia solanacearum upregulates marker genes of the salicylic acid and ethylene signaling pathways but not those of the jasmonic acid pathway in leaflets of Solanum lines during early stage of infection. Eur. J. Plant Pathol. 147:615-625.

Bellincampi, D., Cervone, F., and Lionetti, V. 2014. Plant cell wall dynamics and wall-related susceptibility in plant-pathogen interactions. Front. Plant Sci. 5:228.

Boller, T., and He, S. Y. 2009. Innate immunity in plants: An arms race between pattern recognition receptors in plants and effectors in microbial pathogens. Science 324:742-744.

Cao, J., Lv, Y., Hou, Z., Li, X., and Ding, L. 2015. Expansion and evolution of thaumatin-like protein (TLP) gene family in six plants. Plant Growth Regul. 79:299-307.

Capelli, N., Diogon, T., Greppin, H., and Simon, P. 1997. Isolation and characterization of a cDNA clone encoding an osmotin-like protein from Arabidopsis thaliana. Gene 191:51-56.

Chen, J. L., Liu, K., Miao, C. P., Sun, S. Z., Chen, Y. W., Xu, L. H., et al. 2016. Salt tolerance of endophytic Trichoderma koningiopsis YIM PH30002 and its volatile organic compounds (VOCs) allelopathic activity against phytopathogens associated with Panax notoginseng. Ann. Microbiol. 66:981-990.

Choi, D. S., Hong, J. K., and Hwang, B. K. 2013. Pepper osmotin-like protein 1 (CaOSM1) is an essential component for defense response, cell death, and oxidative burst in plants. Planta 238:1113-1124. 
de Freitas, C. D., Lopes, J. L., Beltramini, L. M., de Oliveira, R. S., Oliveira, J. T., and Ramos, M. V. 2011a. Osmotin from Calotropis procera latex: New insights into structure and antifungal properties. BBA-Biomembranes. 1808:2501-2507.

de Freitas, C. D., Nogueira, F. C., Vasconcelos, I. M., Oliveira, J. T., Domont, G. B., and Ramos, M. V. 2011b. Osmotin purified from the latex of Calotropis procera: Biochemical characterization, biological activity and role in plant defense. Plant Physiol. Biochem. 49:738-743.

Falcao, L. L., Silva-Werneck, J. O., Ramos, A. D., Martins, N. F., Bresso, E., Rodrigues, M. A., Bemquerer, M. P., and Marcellino, L. H. 2016. Antimicrobial properties of two novel peptides derived from Theobroma cacao osmotin. Peptides 79:75-82.

Giraldo, M. C., and Valent, B. 2013. Filamentous plant pathogen effectors in action. Nat. Rev. Microbiol. 11:800-814.

Hakim, A. U., Hussain, A., Shaban, M., Khan, A. H., Alariqi, M., Gul, S., Jun, Z., Lin, S., Li, J., Jin, S., and Munis, M. F. H. 2018. Osmotin: A plant defense tool against biotic and abiotic stresses. Plant Physiol. Biochem. 123:149-159.

Hao, J., Wu, W., Wang, Y., Yang, Z., Liu, Y., Lv, Y., Zhai, Y., Yang, J., Liang, Z., Huang, K., and Xu, W. 2015. Arabidopsis thaliana defense response to the ochratoxin A-producing strain (Aspergillus ochraceus 3.4412). Plant Cell Rep. 34:705-719.

Hong, J. K., Jung, H. W., Lee, B. K., Lee, S. C., and Lee, Y. K. 2004. An osmotin-like protein gene, CAOSM1, from pepper: Differential expression and in situ localization of its mRNA during pathogen infection and abiotic stress. Physiol. Mol. Plant Pathol. 64:301-310.

Jami, S. K., Anuradha, T. S., Guruprasad, L., and Kirti, P. B. 2007. Molecular, biochemical and structural characterization of osmotin-like protein from black nightshade (solanum nigrum). J. Plant Physiol. 164:238-252.

Kumar, S. A., Kumari, P. H., Jawahar, G., Prashanth, S., Suravajhala, P., Katam, R., Sivan, P., Rao, K. S., Kirti, P. B., and Kishor, P. B. K. 2016. Beyond just being foot soldiers-osmotin like protein $(O L P)$ and chitinase (Chi11) genes act as sentinels to confront salt, drought, and fungal stress tolerance in tomato. Environ. Exp. Bot. 132:53-65.

Lee, H., Damsz, B., Woloshuk, C. P., Bressan, R. A., and Narasimhan, M. L. 2010. Use of the plant defense protein osmotin to identify Fusarium oxysporum genes that control cell wall properties. Eukaryot. Cell 9:558-568.

Liu, D., Han, Q., Shah, T., Chen, C., Wang, Q., Tang, B., and Ge, F. 2018. A hybrid proline-rich cell-wall protein gene JSPRP1 from Juglans sigillata Dode confers both biotic and abiotic stresses in transgenic tobacco plants. Trees (Berl.) 32:1199-1209.

Liu, D., Zhao, Q., Cui, X., Chen, R., Li, X., Qiu, B., and Ge, F. 2019. A transcriptome analysis uncovers Panax notoginseng resistance to Fusarium solani induced by methyl jasmonate. Genes Genomics 41:1383-1396.

Miao, Z. Q., Li, S. D., Liu, X. Z., Chen, Y. J., Li, Y. H., Wang, Y., Guo, R. J., Xia, Z. Y., and Zhang, K. Q. 2006. The causal microorganisms of Panax notoginseng root rot disease. Sci. Agric. Sin. 39:1371-1378.

Narasimhan, M. L., Coca, M. A., Jin, J., Yamauchi, T., Ito, Y., Kadowaki, T., Kim, K. K., Pardo, J. M., Damsz, B., Hasegawa, P. M., Yun, D. J., and Bressan, R. A. 2005. Osmotin is a homolog of mammalian adiponectin and controls apoptosis in yeast through a homolog of mammalian adiponectin receptor. Mol. Cell 17:171-180.

Narasimhan, M. L., Damsz, B., Coca, M. A., Ibeas, J. I., Yun, D. J., Pardo, J. M., Hasegawa, P. M., and Bressan, R. A. 2001. A plant defense response effector induces microbial apoptosis. Mol. Cell 8:921-930.

Newton, S. S., and Duman, J. G. 2000. An osmotin-like cryoprotective protein from bittersweet nightshade Solanum dulcamara. Plant Mol. Biol. 44: 581-589.

Onishi, M., Tachi, H., Kojima, T., Shiraiwa, M., and Takahara, H. 2006. Molecular cloning and characterization of a novel salt-inducible gene encoding an acidic isoform of PR-5 protein in soybean (Glycine max [L.] Merr.). Plant Physiol. Biochem. 44:574-580.

Goupil, P., Benouret, R., and Richard, C. 2017. Ethyl gallate displays elicitor activities in tobacco plants. J. Agric. Food Chem. 65:9006-9012.

Pluskota, W. E., Pupel, P., Głowacka, K., Okorska, S. B., Jerzmanowski, A., Nonogaki, H., and Górecki, R. J. 2019. Jasmonic acid and ethylene are involved in the accumulation of osmotin in germinating tomato seeds. J. Plant Physiol. 232:74-81.

Rabouille, C. 2017. Pathways of unconventional protein secretion. Trends Cell Biol. 27:230-240

Ramana Rao, M. V., Parameswari, C., Sripriya, R., and Veluthambi, K. 2011. Transgene stacking and marker elimination in transgenic rice by sequential Agrobacterium-mediated co-transformation with the same selectable marker gene. Plant Cell Rep. 30:1241-1252.

Ramos, M. V., de Oliveira, R. S. B., Pereira, H. M., Moreno, F. B. M. B., Lobo, M. D. P., Rebelo, L. M., Brandão-Neto, J., de Sousa, J. S., Monteiro-Moreira, A. C. O., Freitas, C. D. T., and Grangeiro, T. B. 2015. Crystal structure of an antifungal osmotin-like protein from Calotropis procera and its effects on Fusarium solani spores, as revealed by atomic force microscopy: Insights into the mechanism of action. Phytochemistry 119:5-18.

Rather, I. A., Awasthi, P., Mahajan, V., Bedi, Y. S., Vishwakarma, R. A., and Gandhi, S. G. 2015. Molecular cloning and functional characterization of an antifungal PR-5 protein from Ocimum basilicum. Gene 558:143-151.

Reiss, E., Schlesier, B., and Brandt, W. 2006. cDNA sequences, MALDI-TOF analyses, and molecular modelling of barley PR-5 proteins. Phytochemistry 67:1856-1864.

Sanju, S., Thakur, A., Siddappa, S., Sreevathsa, R., Srivastava, N., Shukla, P., et al. 2015. Retraction note to: Pathogen virulence of Phytophthora infestans: From gene to functional genomics. Physiol. Mol. Biol. Plants 21:167.

Shih, C. T., Wu, J., Jia, S., Khan, A. A., Ting, K. H., and Shih, D. S. 2001. Purification of an osmotin-like protein from the seeds of Benincasa hispida and cloning of the gene encoding this protein. Plant Sci. 160:817-826.

Singh, N. K., Kumar, K. R. R., Kumar, D., Shukla, P., and Kirti, P. B. 2013. Characterization of a pathogen induced thaumatin-like protein gene AdTLP from Arachis diogoi, a wild peanut. PLoS One 8:e83963.

Sripriya, R., Parameswari, C., and Veluthambi, K. 2017. Enhancement of sheath blight tolerance in transgenic rice by combined expression of tobacco osmotin (ap24) and rice chitinase (chi11) genes. In Vitro Cell. Dev.-Pl. 53:12-21.

Tachi, H., Fukuda-Yamada, K., and Kojima, T., Shiraiwa, M., and Takahara, H. 2009. Molecular characterization of a novel soybean gene encoding a neutral PR-5 protein induced by high-salt stress. Plant Physiol. Biochem. 47:73-79.

Tang, B., Li, X., Pu, L., Zhao, Q., Cui, X., Ge, F., and Liu, D. 2019. A pathogenesis-related protein 10 gene PnPR10-3 was involved in molecular interaction between Panax notoginseng and Fusarium solani. Australas. Plant Pathol. 48:447-456.

Tong, Z., Sun, Y., Wang, D., Wang, L. M., Li, L., Meng, X. R., Feng, W. Q., Wurtele, E. S., and Wang, X. C. 2016. Identification and functional characterization of HbOsmotin from Hevea brasiliensis. Plant Physiol. Biochem. 109:171-180.

Van Loon, L. C., Rep, M., and Pieterse, C. M. J. 2006. Significance of inducible defense-related proteins in infected plants. Annu. Rev. Phytopathol. 44:135-162.

Viktorova, J., Rehorova, K., Musilova, L., Suman, J., Lovecka, P., and Macek, T. 2017. New findings in potential applications of tobacco osmotin. Protein Expr. Purif. 129:84-93.

Vos, I. A., Moritz, L., Pieterse, C. M., and Van Wees, S. C. 2015. Impact of hormonal crosstalk on plant resistance and fitness under multi-attacker conditions. Front. Plant Sci. 6:639.

Wang, Q., Oiu, B., Li, S., Zhang, Y., Cui, X., Ge, F., and Liu, D. 2019. A methyl jasmonate induced defensin like protein from Panax notoginseng confers resistance against Fusarium solani in transgenic tobacco. Biol. Plant. 63:797-807.

Zhang, X., Zhou, Q., Wang, X., Cai, J., Dai, T., Cao, W., and Jiang, D. 2016. Physiological and transcriptional analyses of induced post-anthesis thermotolerance by heat-shock pretreatment on germinating seeds of winter wheat. Environ. Exp. Bot. 131:181-189.

Zhang, Y., and Shih, D. S. 2007. Isolation of an osmotin-like protein gene from strawberry and analysis of the response of this gene to abiotic stresses. J. Plant Physiol. 164:68-77. 